\title{
Addendum: Low-value approvals and high prices might incentivize ineffective drug development
}

Vinay Prasad, Christopher McCabe and Sham Mailankody

Nature Reviews Clinical Oncology (2018) https://doi.org/10.1038/s41571-018-0030-2

Published online 15 May 2018

In hindsight, we realize that we could have been more precise when using the terms 'profit' and 'revenue' in our article 'Low-value approvals and high prices might incentivize ineffective drug development'. Total revenue is defined as the receipts from sales ${ }^{1}$. Profit is defined as the excess of the receipts from sales over the spending of a business during any period ${ }^{1}$. Hence, profit is the total revenue minus the costs of a business, over a given period. Profit calculations include credit transactions and asset revaluations as well as cash transactions and changes in the value of real assets ${ }^{1}$.

Nevertheless, this imprecision does not affect the validity of our insight. In our analysis we show that the break-even point for revenue and cost of development (under the specific conditions of our 'thought experiment') would be US $\$ 440$ million. The annual revenue from the sale of many approved cancer drugs now routinely exceeds $\$ 1$ billion, and thus we conclude that "pharmaceutical companies could, hypothetically, turn a profit by testing inert chemical compounds in phase III trials". In the conditions we define in our thought experiment, companies would therefore receive sufficient revenues to make a profit.

\section{References}

1. Black, J., Hashimzade, N. \& Myles, G.A. A dictionary of economics, 4th edn online. (Oxford, 2013). 